\title{
Davi: um homem conforme o coração de Javé?
}

\author{
David: a man after Yahweh's heart?
}

LUIZ JOSÉ DIETRICH ${ }^{\mathrm{a}}$

\section{Resumo}

Este artigo apresenta uma proposta de datação da vida e da chefatura de Davi, a partir da chamada "baixa cronologia", e uma descrição da vida de Davi, a partir das novas proposições da arqueologia e dos estudos críticos da Bíblia. Correlaciona possíveis camadas pré-deuteronomistas dos livros históricos, escavadas dos textos bíblicos, tratados como um "tel" de textos, com descobertas arqueológicas referentes às montanhas centrais da Palestina e de seus entornos. Em seu caminho ao poder Davi torna-se vassalo dos filisteus e avança em meio a muitas mortes. Isso coloca sua ascensão sob muitas suspeitas. O texto tem como pano de fundo o dito de que Davi era um "homem conforme o coração de Javé".

Palavras-chave: Davi. Ascensão de Davi ao poder. Davi e filisteus. Davi e Saul. Davi e Javé.

\section{Abstract}

This article presents a proposal for dating David's life and chiefdom, based on the socalled "low chronology", and a description of David's life, based on the new propositions of archeology and critical Bible studies. Correlates possible pre-deuteronomist layers of historical books, excavated from biblical texts, treated as a "tel" of texts, with archaeological discoveries referring to the central mountains of Palestine and its surroundings. On his way to power David becomes a vassal of the Philistines and advances amid many deaths. This puts his ascension under many suspicions. The text has as its background the saying that David was a "man after the heart of Yahweh".

Keywords: David. David's rise to power. David and the Philistines. David and Saul. David and Yahweh.

\footnotetext{
a Pontifícia Universidade Católica do Paraná (PUCPR), Curitiba, PR, Brasil. Doutor em Ciências da Religião

- Literatura e Sociedade do Mundo Bíblico, e-mail: luiz.dietrich@pucpr.br
} 


\section{Introdução}

Os estudos do Antigo Israel são fortemente impactados pelas proposições da nova arqueologia que, revisando a chamada "arqueologia Bíblica", desmontam várias concepções que perduraram por muitos anos (FINKELSTEIN; SILBERMAN, 2003, p. 35-41). A teoria documentária foi fortemente questionada (SKA, 2016, p. 24-43), especialmente pela negação dos dados fornecidos como provas arqueológicas da existência do império davídico-salomônico. A epigrafia, estudada dentro desta mesma vertente arqueológica, aponta os séculos VIII e VII a.C. como o momento dos primeiros passos significativos na elaboração da Bíblia Hebraica (FINKELSTEIN; SILBERMAN, 2003, p. 40; SCHNIEDEWIND, 2011; CARR, 2011, p. 304-338.). Juntese a isso a constatação de que a concepção politeísta predominava no Israel pré-exílico: muitos testemunhos revelam o culto a uma grande diversidade de Deuses e Deusas, em que El, Javé, Asherá, Baal e Elohim eram cultuados tanto em Israel, no norte, como em Judá, no sul (SMITH, 1990; DAY, 2000; REIMER, 2009, p. 21-52; ANDERSON, 2015).

Os indícios arqueológicos revisados e ou levantados nas últimas décadas revelam um início bem mais modesto para Israel e principalmente para Judá. A existência de um reino unido nos tempos de Davi e Salomão, como descrito em 2Sm - 1Rs, é praticamente descartada (FINKELSTEIN; SILBERMAN, 2003, p. 174203). Com isso também cai por terra o tradicional discurso linear que apresentava a história de Israel em períodos sequenciados: tribos - monarquia unida - divisão da monarquia, que se sucediam na história. E, como escrito acima, a tradicional teoria documentária, que orientou os estudos e debates sobre o Pentateuco e vários dos Livros Históricos por dezenas de anos, que já há tempos era questionada, precisa se não ser abandonada, pelo menos ser revista'.

A história de Israel passou a ser a questão no centro do debate. Devido à inexistência de testemunhos arqueológicos expressivos para os inícios de Israel até o estabelecimento das monarquias de Israel e de Judá, discute-se até

\footnotetext{
${ }^{1}$ Joel S. Baden, na obra: The composition of the Pentateuch. Renewing the documentary Hypothesis. (The Anchor Yale Bible Reference Library. New Haven/London: Yale University Press, 2012), revisa-a e defende que esta hipótese ainda se mantém de pé.
} 
mesmo a possibilidade de se escrever uma história do Israel Antigo². Há ainda muitas lacunas a serem preenchidas. Pesquisadores brasileiros também procuram ajudar no processo de uma nova compreensão da História de Israel e da própria Bíblia (ZABATIERO, 2013; KAEFER, 2015; REIMER, 2017). Esse artigo, sobre Davi e o período em que esteve à frente da unidade política centrada em Jerusalém, quer somar-se a estes esforços. É uma sequência do que foi trabalhado em um artigo, sobre Saul como o chefe de uma unidade política na região montanhosa central de Israel ${ }^{3}$. Aqui será apresentada uma proposta de reconstrução histórica de Davi, suas origens, sua ascensão ao poder em Jerusalém, os limites de sua "jurisdição" e algumas características dele próprio e de seu domínio ${ }^{4}$. Nesta reconstrução usaremos a datação proposta pela "baixa cronologia" (FINKELSTEIN; PIAZETSKY, 2011, 50-54), que nos parece estar apoiada em uma avaliação cientificamente mais precisa dos achados arqueológicos.

\section{A arqueologia em busca de Davi}

A arqueologia até o momento não encontrou nada que possa ser vinculado diretamente a Davi. A arqueóloga Eilat Mazar, prima do renomado arqueólogo Amihai Mazar, desde 2005 escava a área chamada de "grande estrutura de pedra" ("large stone structure"), que fica na parte norte da área conhecida como "Cidade de Davi", localizada fora dos muros atuais de Jerusalém. Incluída nesta "grande estrutura de pedra" está outra, construída contra a lateral de uma encosta, que se assemelha a um muro de arrimo ou a

\footnotetext{
2 Para uma introdução no debate sobre a história de Israel ver: DA SILVA, A. J. A história de Israel na pesquisa atual. In: FARIA, J. F. (Org.). História de Israel e as pesquisas mais recentes. Petrópolis: Vozes, 2003, p. 41-87; e ZABATIERO, J. P. T. Uma história cultural de Israel. São Paulo: Paulus, 2013 p. 31-53.

3 DIETRICH, L. J. Quem matou Saul? Revista Estudos de Religião, São Paulo, v. 34, n. 1, p. 225-254, jan./abr. 2020.

${ }^{4}$ Estes dois artigos fazem parte de um projeto mais amplo, ousado e ambicioso, de escrever um livro atualizado - com base na arqueologia, na epigrafia e nos estudos críticos da Bíblia - sobre a História de Israel, que deverá ser lançado pela Paulus no início de 2021. O projeto é coordenado pelo Centro Bíblico Verbo de São Paulo: Luiz José Dietrich (origens de Israel e das monarquias); José Ademar Kaefer (de Jeroboão e Roboão até a reforma de Josias); Shigeyuki Nakanose (período babilônico); Antônio Carlos Frizzo (período persa) e Maria Antônia Marques (período grego).
} 
uma escadaria muito rústica, por isso chamada de "stepped stone structure" Em 2006 Eilat Mazar escreveu que teria encontrado o palácio de Davi naquele lugar (MAZAR, 2006, p. 16-27; 2007, p. 61-62; 2009, p. 32-60). Eilat Mazar defendeu que o complexo com as duas estruturas era parte do palácio de Davi, sendo então um achado arqueológico que podia ser diretamente vinculado a Davi. Teve apoio de Amihai Mazar e de Avraham Faust. Porém, enquanto Eilat Mazar acredita que a toda a "grande estrutura de pedra" foi construída por Davi, Amihai Mazar (2010, p. 45) e Faust (2010, p. 127) afirmam que esta estrutura pertencia ao forte jebusita conquistado por Davi. Entretanto, numa primeira reavaliação, Finkelstein, Herzog, Singer-Avitz e Ussishkin defendem que toda a estrutura seria do período helenístico (FINKELSTEIN et al, 2007); e um pouco mais tarde Finkelstein, Fantalkin e Piasetzky (2008) aceitam a possibilidade de que alguns achados sejam da época do Ferro II, cerca de 850750 a.C. Alguns anos mais tarde Finkelstein reafirma estas conclusões (2011, p. 9).

Portanto, continuamos sabendo quase nada sobre o Davi histórico. Fora da Bíblia, até o presente momento, há somente um testemunho indireto de sua existência: o nome Davi que aparece na chamada "estela de Dã". Esta estela teria sido erigida pelo rei Hazael, de Damasco/Aram, por volta de 841 a.C., celebrando sua vitória sobre uma coalizão formada pelo rei Jorão, que governou Israel mais ou menos entre 851 a 841 a.C., e pelo rei Ocozias, que foi rei de Judá em 841 a.C. A estela menciona Davi indiretamente, ao referir-se a Ocozias como rei da "casa de Davi", BYT-DWD (RAINEY, 1994, p. 47; KAEFER, 2012, p. 40). Para a maioria dos estudiosos isto é uma prova extra bíblica da existência de Davi e do seu reinado. Há, no entanto, alguns estudiosos que contestam que as três consoantes (DWD) que ali aparecem refiram-se mesmo a Davi (DAVIES, 1994, p. 54-55; ATHAS, 2003, p. 225-226). Do mesmo modo nem Saul e nem Salomão são testemunhados fora da Bíblia.

\footnotetext{
${ }^{5}$ Ver imagens destas estruturas em: https://israelfinkelstein.files.wordpress.com/2013/07/largestone-structure-zdpv1.pdf
} 


\section{Fazendo arqueologia na Bíblia}

Assim sendo, para uma reconstrução hipotética do Davi histórico nos basearemos especialmente na leitura crítica da Bíblia em diálogo com a arqueologia em diversos aspectos relacionados ao contexto e ao período no qual situamos a vida pública de Davi. Com as devidas precauções, parte do texto bíblico sobre Davi pode ser também um indicativo de sua existência histórica. É o caso da narrativa conhecida como "História da ascensão de Davi ao trono" (1Sm 16 - 2Sm 6). Os limites desta narrativa, o contexto e a data em que teria sido escrita ou composta são muito discutidos. Mas a imagem de um Davi heroico, amado por muitos, defensor de seu povo contra ameaças estrangeiras, um exemplo de seguidor dos valores tradicionais de Israel, escolhido e conduzido por Javé ao poder, é possivelmente uma peça de “propaganda régia” (McCARTER, 1980, p. 489-504), elaborada como resposta a acusações de que, ao contrário disso, ele teria sido um violento guerreiro, sanguinário e usurpador do poder (2Sm 16,7-8). Mas, "mesmo sendo este o caso, isto significa que houve um Davi que viveu e governou de um jeito ou de outro" (LEUCHTER; LAMB, 2016, p. 189).

Davi, apresentado na Bíblia como "um homem conforme o coração de Javé" (1Sm 13,14) $)^{6}$, é uma figura controversa. "Ele é considerado um santo padroeiro da oração, mas a morte e a destruição seguem-no para onde quer que vá no livro de Samuel" (LEUCHTER; LAMB, 2016, p. 188). E como nossa principal fonte de informação sobre ele é a Bíblia, corremos o risco de que nossa "avalição de Davi tenha menos a ver com Davi do que com nossas pré concepções sobre a narrativa bíblica" (BOSWORTH, 2006, p. 191). A interpretação tradicional, que o vê como um piedoso pastor que, guiado por Javé, tornou-se o rei de Israel, é geralmente apresentada por aqueles que fazem uma leitura ingênua ou direta do texto bíblico. Leituras críticas, que partem da "hermenêutica da suspeita" tendem a retratá-lo como um

\footnotetext{
${ }^{6}$ Citação segundo a Bíblia de Jerusalém. São Paulo: Paulus, ed. Revista e ampliada, 2002.
} 
"usurpador astuto que assassina e planeja seu caminho para um trono que por direito não é seu" (BOSWORTH, 2006, p. 191-192)7.

Neste artigo, cuja abordagem se insere na perspectiva das leituras críticas, será buscado um diálogo entre o texto bíblico e a arqueologia. Como os arqueólogos retiram suas informações do tel de terra ${ }^{8}$, os textos bíblicos, recentes ou antigos, serão tratados como uma espécie de tel de textos, também frutos da história de Israel, e onde igualmente podem ser encontradas marcas dessa história. O diálogo e a cooperação entre as várias ciências, com especial destaque para a exegese crítica, a moderna arqueologia e a epigrafia, parece-nos fundamental para que sejamos capazes de dar conta dos desafios no campo da história de Israel e da Bíblia (conforme LIVERANI, 2008, p. 14). Procuraremos tomar a sério a proposição de Bosworth e oferecer uma reconstrução mais complexa do que simplesmente "tomar a apologia como um indiciamento e o indiciamento como história" (2006, p. 197), como em grande parte fazem Steven L. McKenzie (2000), Baruch Halpern (2001), e Joel Baden (2016). O tema é bem amplo e complexo, pois

O leque de pontos de vista sobre a história de Davi abrange desde a confiança geral na confiabilidade histórica da história bíblica, a confiança na confiabilidade histórica da história bíblica quando lida como propaganda, até a desconfiança de que se possa dizer que houve um Davi histórico (BODNER; JOHNSON, 2019, p. 121).

\section{Os inícios de Davi na Bíblia}

A Bíblia nos apresenta três narrativas sobre como Davi entra na história da monarquia. A primeira é a narrativa da "unção de Davi" (1Sm 16,1-13). Porém esta unção não será citada e nem é pressuposta em $15 \mathrm{Sm}$ 17, quando Davi atua entre seus irmãos no exército de Saul, nem em qualquer outra parte da história de Davi. Nem mesmo em 2Sm 2,4, quando os "homens de Judá"9 ungiram a Davi como rei da "casa de Judá", ou em 2Sm 5,3 quando se diz que "todos os anciãos de Israel" ungiram a Davi como "rei de todo Israel". Portanto é bem

\footnotetext{
7 Este autor também fornece um breve apanhado sobre as principais caracterizações de Davi na pesquisa dos últimos 40 anos.

$8 \mathrm{Te} / \mathrm{na}$ arqueologia é uma colina ou um monte artificial formado por diversas camadas de restos de ocupação e construções humanas que foram sobrepostas umas às outras ao longo da história. ${ }^{9}$ As citações bíblicas, salvo indicação em contrário, serão retiradas da Nova Bíblia Pastoral (São Paulo: Paulus, 2014).
} 
provável que a narrativa da unção de Davi em 1 Sm 16 seja uma criação literária posterior e não represente um fato histórico.

A segunda (1Sm 16,14-23) é a narrativa que nos apresenta Davi sendo chamado à corte de Saul como uma espécie de "musicoterapeuta", para acalmar ao rei Saul quando ele entrava em crise, tomado por um "mau espírito enviado por Javé". Nesta narrativa, entre outros atributos, Davi é apresentado como sendo um "valente guerreiro" $(16,18)$. Saul gosta muito de Davi e requisita-o para que fique junto dele como "seu escudeiro" (16,21). Esta narrativa é de uma fonte independente e cria conflitos com a narrativa seguinte, $15 \mathrm{Sm}$ 17. A apresentação de Davi como "musicoterapeuta" faz parte de uma narrativa maior, elaborada para diminuir o brilho de Saul e apresentar e justificar a derrota de sua família e a vitória de Davi como um movimento patrocinado por Javé. Desgostoso com Saul, Javé afasta seu Espírito de Saul, enviando para ele somente um "mau espírito" $(16,14)$ e fazendo pousar seu Espírito sobre Davi “desse dia em diante" (16,13; cf. 16,18). Essa narrativa teria sido criada posteriormente.

A terceira é a que conhecemos como a "luta de Davi contra Golias" ( $1 \mathrm{Sm}$ 17,1-18,5). É possível que as informações históricas sobre como Davi tenha entrado no círculo mais próximo dos homens de Saul estejam no substrato primitivo desta narrativa ${ }^{10}$. Aqui, ao contrário de $1 \mathrm{Sm} 16,18$, Davi é um menino inexperiente em guerras (17,33.38-39); sua presença no campo de batalha, que seria normal sendo o escudeiro de Saul (1Sm 16,21), é questionada e tida como imprudente por seu irmão mais velho $(17,28)$ e nem Saul nem Abner, seu principal general, conhecem Davi (17,55-58). $1 \mathrm{Sm} 17$ nos apresenta um pequeno menino enfrentando e vencendo um gigante guerreiro muito bem armado. Porém por baixo dessa imagem mitificada pode-se perceber que Davi era um guerreiro anônimo do exército de Saul e tinha uma "tenda" no campo de

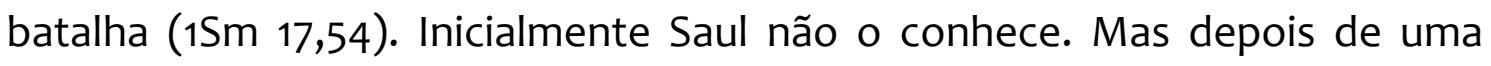
corajosa e eficiente atuação, onde provavelmente Davi enfrentou, armado com uma funda, um guerreiro armado com armas de ferro - talvez o chefe de um destacamento filisteu - e com sua vitória ajudou os israelitas a vencerem aquele confronto com alguns filisteus, Saul chama Davi a sua presença e Ihe

\footnotetext{
${ }^{10}$ Ver uma exegese detalhada desta perícope em Dietrich (2002).
} 
pergunta quem é seu pai ( $1 \mathrm{Sm}$ 17,55-58), e requisita-o para fazer parte do grupo de militares que estavam mais próximos dele (1Sm 18,3; cf. 14,52).

\section{Os inícios de Davi na história}

Possivelmente algo assim tenha ocorrido historicamente. Davi entra na história como um guerreiro sob o comando de Saul. Esta deve ter sido uma de suas virtudes: ser um bom guerreiro (MILLER; HAYES, 2006, p. 161; GALLAZZI, 2011, p. 75). Devia ser também um bom estrategista. Alguém que "não dá pontos sem nó". Vitorioso nas tarefas que lhe eram designadas, Davi torna-se chefe dos "homens de guerra" $(18,5 ; 18,13)$ e, como oficial do exército de Saul, Davi casa-se com Micol, uma das filhas de Saul, entrando na corte e na família de Saul e tornando-se apto a pleitear a sucessão. O rápido crescimento de Davi dentro do exército de Saul e ações como seu casamento com uma das mulheres do clã de Saul parecem indicar que Davi buscava entrar na linha sucessória. Os textos da chamada "História da ascensão de Davi ao trono" (1Sm 16 - 2Sm 6), produzidos pela casa de Davi, procuram mostrar enfaticamente que Davi não conspirou para chegar ao poder. A transferência do poder de Saul para Davi teria sido decisão e obra de Javé (1Sm 13,13-14; 15,11.23.28; 16,1.12-13).

Mas historicamente parece ter existido uma forte suspeita de que Davi conspirou para chegar ao poder. Sua ação, subindo degraus em busca do poder, chama a atenção da família de Saul e Davi é obrigado a fugir. No deserto Davi forma um bando com "todos os oprimidos, todos os endividados e todos os descontentes" (1Sm 22,2). Provavelmente gente que perdeu sua autonomia ou suas terras com o crescimento do poder e a interferência dos donos de bois (SCHWANTES, 2008, p. 24; DIETRICH, 2020, p. 237-238), capitaneados por Saul, no tradicional sistema de distribuição das terras ( $1 \mathrm{Sm} 22,7)$. Davi junta ao redor de si cerca de seiscentos homens ( $1 \mathrm{Sm} 23,13 ; 25,13 ; 27,2 ; 30,9)$. Com isso acirrase o confronto: de um lado um exército mantido pela elite da sociedade e de outro um bando de marginalizados se organizando militarmente, mas que precisa manter-se com saques e tributos (1Sm 25,7-8).

É possível que tenha sido nesse meio, no deserto e ao lado dos excluídos, dos semterra, que nasceu a história popular de um líder chamado Davi [...], um líder popular 
que comandava um bando de excluídos, a estilo dos antigos hebreus-hapirus e que atuava no sul de Judá, entre Hebron, Bersheva e Siceleg (KAEFER, 2015, p. 44).

\section{Davi vassalo dos filisteus}

Em sua fuga Davi irá juntar-se aos filisteus. Será um mercenário dos filisteus. Esta deve ser considerada uma informação histórica. A palavra "filisteus", na pesquisa atual, compreende diversos grupos em que se mesclavam e se misturavam várias raízes étnicas e culturais, "um fenômeno trans regional de vigorosos bandos de guerreiros com antecedentes da região do Mar Egeu e da Anatólia, ativo em todo o oeste do Mediterrâneo durante os últimos séculos do final do segundo milênio a.C." (KOCH, 2017, p. 192-193). A partir do século XIII começaram a chegar nas planícies costeiras de Canaã, ainda no tempo de Ramsés II. Vieram em muitas levas de diversas origens, em vários movimentos migratórios e com diferentes trajetórias. A cultura filisteia emerge em Canaã como fruto de um complexo processo de muitas décadas, envolvendo "muitos vetores, múltiplas origens, diversas experiências socioeconômicas dos diversos povos que se amalgamaram aos filisteus" (MAEIR; HITCHKOCK, 2017, p. 248). Os filisteus também não tiveram um único centro gravitacional. Abandona-se a ideia de uma Pentápolis filisteia, que parece ter sido deduzida mais das narrativas bíblicas do que da observação arqueológica ( $\mathrm{KOCH}, 2017$, p. 193-196). O centro do poder filisteu foi mudando durante o curso da Idade do Ferro de uma localidade para outra:

No Ferro I Ekron era o centro, assentamento importante e talvez o maior da Filistia. Sua destruição no final do séc. X abriu o caminho para a ascensão de Gat, que chegou em seu auge no meio do séc. IX. E quando Gat foi destruída [...] (FINKELSTEIN, 2007, p. 521).

Os camponeses israelitas irão enfrentar e resistir ao avanço filisteu que provavelmente foi comandado a partir de Gat. Gat foi uma grande e próspera cidade desde o início do Ferro I (ao redor do ano 1200 a.C.) até o final do Ferro IIA, quando foi destruída por Hazael, aproximadamente no ano 830 a.C. Era uma extensa cidade, incluindo uma parte alta e uma parte baixa, com cerca de 40 a 50 hectares, o que fazia dela "uma das maiores cidades do Levante naquele tempo" (MAEIR; HITCHKOCK, 2017, p. 253). E apesar de os textos 
bíblicos apontarem um domínio judaíta sobre os filisteus, "se alguém quisesse falar de reinos dominantes no sul do Levante, no Ferro IIA, o reino de Gat seria um candidato muito mais provável do que o nascente reino de Judá" (MAEIR; HITCHKOCK, 2017, p. 253) ${ }^{11}$. É Gat que emerge como o centro político dominante neste período. Mesmo com relações bidirecionais com a Filistia no oeste e com a Shefelá e as regiões das montanhas centrais a leste, "é seguro admitir que o reino de Gat irradiava poder tanto para oeste como para leste" (MAEIR; HITCHKOCK, 2017, p. 255). E nisso as narrativas bíblicas sobre Davi combinam com a arqueologia (1Sm 17,4.52; 21,11; 27,2): é com eles que Davi irá se relacionar e é para eles que ele irá trabalhar.

Estes filisteus foram os maiores inimigos de Israel no período. O fato de Davi ter atuado ao lado dos filisteus pesa como uma grave mancha em seu currículo. É difícil pensar que a família de Davi, que tomou o comando de Benjamim e de Judá depois que Saul e sua família foram mortos pelos filisteus, e é quem faz a redação final do texto, teria inventado tal coisa, mas também não podiam simplesmente apagar isso da história de Davi. O fato era conhecido pelos membros dos clãs de Benjamim e por muitos que receberam as memórias dos que viveram aquele período.

O que a casa davídica faz então é criar uma narrativa muito bem elaborada na qual se esforçam para inocentar Davi. O fato é que os textos informam que até o dia em que os filisteus decidiram subir contra o exército de Israel e mataram Saul, Jônatas e outros filhos de Saul, Davi era mercenário dos filisteus (1Sm 28,1-2; 29,2-3). Como o texto bíblico escrito pela casa davídica admite inclusive que o bracelete usado por Saul e a coroa dele estavam em posse de Davi depois da batalha (2Sm 1,10), Davi muito possivelmente esteve ao lado dos filisteus na batalha do monte Gelboé (1Sm 31,1-3) em que Saul e seus filhos foram mortos (HALPERN, 2001, p. 78-81; BADEN, 2016, p. 113). Assim, o tempo da chefatura de Saul deve ter iniciado por volta do ano 980 até mais ou menos 958 a.C., quando foi morto (datação adaptada a partir da proposta fornecida por LIPINSKI, 2018, p. 49-63).

\footnotetext{
${ }^{11}$ Contra Avram Faust, que em seus escritos sustenta que no séc. $X$ a.C., particularmente no tempo do rei Davi, os filisteus eram política e culturalmente dominados pelo reino de Judá (FAUST, 2013; 2018; 2019).
} 


\section{O caminho para o trono}

Não foram somente as mortes de Saul e seus filhos que marcaram o caminho de Davi até o trono. As acusações de conspiração e assassinato que pesavam contra Davi nos são transmitidas através das palavras de um Benjaminita, da família de Saul, chamado Semei, que grita contra Davi: "Vá embora, fora daqui homem sanguinário, homem perverso! Javé fez recair sobre você todo o sangue da casa de Saul, cujo reino você usurpou! [...] Eis que agora você está na desgraça, pois você é um homem sanguinário!"' (2Sm 16,58). “Essa passagem parece desvelar o que as narrativas bíblicas tentam encobrir" (KAEFER, 2015, p. 43). Na “História da ascensão de Davi ao Trono" (1Sm 16 - 2Sm 6), escrita exatamente para inocentar Davi diante destas acusações, menciona-se a morte de Abner, o principal comandante do exército de Saul (2Sm 3,27), e de Isboset/Ishbaal, outro filho de Saul $(2 \mathrm{Sm} \mathrm{4,6).}$

As acusações contra Davi são graves: conspiração, usurpação do poder e assassinatos (1Sm 20,30-31; 22,13). A História da ascensão de Davi diz que ele não buscou o poder, não tramou para tomá-lo e nem matou para alcançá-lo. Apresenta-o como fiel servo de Saul, que teve de buscar refúgio entre os filisteus para proteger a si mesmo e a sua família da inveja e da fúria insana de Saul. Essa narrativa também quer fazer acreditar que Davi teve a oportunidade de matar Saul por duas vezes, mas não ousou "levantar a mão contra” o ungido de Javé (1Sm 24,7; 26,9.11.23), tendo inclusive jurado a Saul "não exterminar" sua descendência e nem "fazer desaparecer" o nome de Saul e do pai dele (1Sm 24,22-23). A narrativa também conta que Davi enganava os filisteus, que fingindo servir aos interesses dos filisteus, atacava os inimigos de Judá (1 Sm 27), e que Davi foi dispensado do exército filisteu e não estava entre eles quando os filisteus mataram Saul e seus filhos na batalha do monte Gelboé (1Sm 31). Afirmam que Javé estava com Davi e conduzia a história dessa forma, e atribuem a Javé a morte de Saul no campo de batalha $(1 \mathrm{Sm} \mathrm{26,10).}$

No entanto, historicamente, Davi só consegue formar o reino de Judá, e também assumir o poder sobre parte do território Benjaminita de Saul, no Israel norte, após a morte de Saul, de todos os seus filhos capacitados para a sucessão e também do comandante do exército de Saul. 


\section{Davi em Hebron, a família de Saul em Maanaim: dois pequenos reinos em guerra}

Possivelmente Davi se faz rei de Hebron em 958 a.C., logo depois da morte de Saul e da destruição de seu exército ${ }^{12}$. 1Sm 27,8-12; 30,26-31 mostram que Davi parece ter preparado sua volta para Judá enviando presentes aos líderes de importantes clãs do sul de Judá (DIETRICH, 2007, p. 179), articulando a formação da tribo de Judá juntamente com sua entronização em Hebron. Para conseguir isso Davi pode ter ocupado e tomado Hebron militarmente (SCHWANTES, 2008, p. 24). Durante o reinado de Saul provavelmente a região da montanha de Judá era parte dos domínios da tribo de Benjamim. Há textos bíblicos indicando que as montanhas de Judá estavam associadas à tribo de Benjamim ( Jz 1,21; Js 18,28) e um grande número de indícios de que o território controlado pelos benjaminitas ia até uns 40 ou $50 \mathrm{~km}$ ao sul de Jerusalém. Portanto, Hebron, que fica no ponto mais alto da montanha de Judá, e Carmel na descida sul na direção do Negev, estariam dentro das terras de Benjamim. De fato, nessa época, "a região montanhosa de Judá, ao sul de Jerusalém foi habitada de maneira escassa por apenas um pequeno número de assentamentos" (FINKELSTEIN, 2015, p. 64.). Estima-se que a população da região montanhosa central de Benjamim, Efraim e Manassés, era de aproximadamente 38 mil pessoas, enquanto nas montanhas de Judá viviam somente pouco mais de 2 mil pessoas (GRABBE, 2007, p. 92).

A organização de Judá como tribo e a sagração de Davi como rei Hebron (2Sm 2,1-4) dificilmente poderiam ser feitas sem o consentimento dos filisteus. Os textos bíblicos informam a respeito de vários combates entre Davi e os filisteus com vitórias de Davi (1Sm 23,1-5; 2Sm 5,17-21.22-25; 8,1), porém, estas narrativas apresentam poucos elementos que permitam uma confirmação e

\footnotetext{
12 Discordando de Lipinski (2018, p. 52) e de Knauf e Guillaume (2016, p. 72-73). Embora com argumentos diferentes, ambos defendem que Davi formou a tribo de Judá e tornou-se rei em Hebron ainda quando Saul estava vivo. Dado que a força de Saul parece ter sido grande, a ponto de Davi ter de fugir e abrigar-se entre os filisteus, e que estes tiveram de fazer uma grande campanha militar, inclusive com apoio da guarnição egípcia estacionada em Betsã $(1 \mathrm{Sm} 31,10)$, para derrotar o exército de Saul, não nos parece possível que Davi tenha podido arrancar um pedaço do território de Saul antes de ele ser vencido (ver também nota 13 a seguir).
} 
dificilmente podem ser consideradas históricas ${ }^{13}$. Muito provavelmente Davi continuou sendo vassalo dos filisteus durante todo o seu reinado em Hebron e também em Jerusalém (DIETRICH, 2007, p. 179; HALPERN, 2017, p. 338-339).

Apesar de tudo, os remanescentes da família de Saul ainda tiveram forças para juntar o que restou de seus componentes e do exército de Saul em Maanaim (2Sm 2,8-10). Maanaim situa-se na Transjordânia, na região de Jabes de Galaad, longe do alcance de Davi e dos filisteus. Isto confirma os laços desta região com a família de Saul. Foi em Jabes (1Sm 11,1-11) que Saul articulou forças para começar sua luta para expulsar os filisteus da região montanhosa central de Israel (DIETRICH, 2020, p. 236).

Saul teve vários filhos com Aquinoan, sua esposa: Jônatas, Abinadab, Melquisua e Jesui, e também duas filhas: Merob e Micol (1Sm 14,49-30 e 31,2). Em Maanaim a família de Saul reaglutina-se em torno de um dos filhos de Saul, do qual não sabemos o nome certo. Jônatas, Abinadab e Melquisua morreram, juntamente com Saul, na guerra com os filisteus (1Sm 31,2). A Bíblia apresenta este quarto filho de Saul ora como nome de Isboset (2Sm 2,8.10.12; 3,8.14.15; 4,5.8.12), ora com o nome de Isbaal $(1 \mathrm{Cr} 8,33 ; 9,39)$ e ora com o nome de Jesui (1Sm 14,49). Isbaal significa "homem de Baal". Esse pode ter sido o nome verdadeiro deste filho de Saul, mas também pode ser mais uma das maneiras usadas pelas redações posteriores para deturparem a memória de Saul, ligando-o ao culto a Baal, uma divindade que será posteriormente execrada em Israel. Para Dietrich (2007, p. 168) seu nome verdadeiro teria sido Ishyo, "homem de Javé", que na Bíblia aparece como Jesui (1Sm 14,49). Javé teria sido substituído por Baal em seu nome para difamar Saul e seu filho. Isboset significa "filho da vergonha"; dificilmente algum pai ou mãe daria um nome assim para um filho. Este nome é sem dúvida fruto de redações posteriores, após a proibição do culto a Baal, quando os redatores substituíram Baal por "vergonha". Um processo semelhante deve ter acontecido com o filho de

\footnotetext{
${ }^{13}$ Knauf e Guillaume (2016, p. 72) pensam que Davi foi coroado em Hebron ainda antes da morte de Saul e que teria havido uma divisão entre filisteus de Gat (com Davi), e de Ekron (com Saul), considerando que a narrativa de uma vitória de Davi sobre os filisteus (de Ekron) pode ser histórica (2016, p. 72-73). Lipinski por sua vez considera-a "uma lenda" (a legend) (2018, p. 53).
} 
Jônatas e neto de Saul, que na Bíblia aparece como Mefibaal/Mefiboset (2Sm 4,4; 9,6-13), e como Meribaal (1Cron 8,34; 9,40).

Mas, seja como for, o restante da família e do exército de Saul continuarão organizados em Maanaim e, a partir dali, por aproximadamente seis ou sete anos depois da morte de Saul, tentarão rearticular o poder da casa de Saul (Cf. 2Sm 3,1) $)^{14}$, mas não terão sucesso. Tanto o filho de Saul, que o sucedeu, como Abner, o principal comandante do exército da família de Saul, serão mortos por subalternos ou aliados de Davi. Primeiro foi morto Abner (2Sm 3,6-27) e depois Isbaal/Isboset (2Sm 4,1-8). A narrativa da História da ascensão de Davi ao Poder, no entanto, inocenta Davi destes assassinatos. Em 2Sm 3,28-39 Davi é inocentado da morte de Abner e em 2Sm 4,9-12 é inocentado da morte de Isboset ${ }^{15}$.

A narrativa bíblica mostra Davi tomando todos os cuidados para eliminar ou controlar todos os remanescentes da casa de Saul que pudessem reclamar seus direitos sucessórios. Assim Davi mandará buscar Mefibaal/Mefiboset/Meribaal, filho de Jônatas, neto de Saul, e o manterá dentro das muralhas de Jerusalém (2Sm 9,1-3). Fez com ele o mesmo que já havia feito com Micol, a filha de Saul: colocou ambos dentro das muralhas de Jerusalém, onde pudessem ser vigiados e controlados, em uma espécie de "prisão domiciliar". Pior sorte terão os filhos que Saul teve com sua concubina chamada Resfa e os filhos que Micol havia tido com outro marido. Todos foram entregues aos gabaonitas, antigos inimigos de Saul, que os massacraram (2Sm 21,1-10). Assim, por volta dos anos 952-951 a.C., termina o reino Benjaminita da casa de Saul. Davi consolida sua posição entrando em Jerusalém e com isso a casa de Saul definhará e praticamente desaparecerá.

Semei, um membro influente da casa de Saul, que de acordo com os relatos bíblicos consegue reunir "mil homens", será ainda citado algumas vezes $(2 \mathrm{Sm} 16,5-8 ; 19,17-310$. Mas as tribos do norte, Efraim e Manassés, ficarão

\footnotetext{
${ }^{14} 1 \mathrm{Sm} \mathrm{2,10}$ afirma que Isbaal reinou somente dois anos. Porém, o tempo de duração do reinado de Isbaal pode ter sido adulterado da mesma forma que foi adulterado o tempo de duração do reinado de Saul, seu pai $(1 \mathrm{Sm} 13,1)$. Isto pode ser resultado de uma "revisão maliciosa" posterior que visava diminuir a importância de Saul e de engrandecer a figura de Davi (LIPINSKI, 2018, p. 51).

${ }^{15}$ Enquanto a "História da ascensão de Davi ao trono" inocenta Davi da morte de seus inimigos, a "História da sucessão de Davi", ou da ascensão de Salomão ao Trono, irá atribuir a Davi a culpa pela morte de seu aliado Joab (1Rs 2,1-6).
} 
por aproximadamente duas décadas sem uma organização política e militar eficiente. É possível que durante esses anos de desorganização a região tenha sofrido incursões e domínio de filisteus, de egípcios baseados em Betsã e até mesmo de Davi. É possível que as narrativas a respeito da revolta de Absalão (2Sm 15-18) e, especialmente, da revolta de Seba (2Sm 20) tenham origem em tentativas de resistência e rearticulação dos camponeses nortistas, que, entretanto, foram derrotadas.

Então, para a cronologia do norte, aqui se propõe - uma novidade não colocada ainda por outros pesquisadores - que, após a chefatura de Saul, o norte passou por um lapso de tempo sem governo e só conseguirá se reorganizar ao redor dos anos 927 a.C., com Jeroboão I, na "entidade territorial norte israelita ao redor de Siquém - Tersa”, em Efraim (FINKELSTEIN, 2015, p. 30).

E, falando em cronologia, é necessário neste ponto abrir um parêntese para chamar a atenção para as datas aqui adotadas. As datas aqui fornecidas também em outros autores - são aproximativas e hipotéticas. Não há como ser diferente. Embora seja muito provável que Saul, Davi, Salomão e também Jeroboão tenham existido e reinado, seguindo a "baixa cronologia" (Low Chronology), entre os anos 1000 e 900 a.C., até o momento não existe nenhuma fonte segura que permita afirmar com mais precisão as datas de início e fim destes reinados. A história dos começos de Israel foi a mais abalada pelas recentes proposições da arqueologia. Como já foi escrito acima, o caminho adotado neste artigo, após considerar e analisar o que é afirmado pela maioria dos pesquisadores a respeito do antigo Israel - no estudo crítico da Bíblia e na arqueologia -, foi o de adaptar a cronologia apresentada para Saul, Davi e Salomão por Edward Lipinski (2018, p. 49-63). Pois esta toma em consideração e permite apresentar uma possível sequência dos acontecimentos nos inícios dos reinos de Israel e de Judá, numa narrativa que seja coerente com os dados arqueológicos e informações históricas presentes nas camadas pré-deuteronomistas das narrativas bíblicas (GRABBE, 2007, p. 121).

Já com a datação de Jeroboão I, que deve ter governado entre 927-905 a.C., e com os reis seguintes, é possível ser mais preciso e inclusive apoiar-se 
na ordem e na cronologia que a Bíblia nos apresenta. Falando da lista de reis iniciando com Jeroboão I e Roboão, até mesmo Israel Finkelstein, um dos representantes da nova arqueologia, afirma:

\begin{abstract}
Não vejo razão para duvidar dos nomes, ordem e datas desses reis. A ordem dos monarcas israelitas e judaítas, com a duração de reinado e informações cruzadas entre os dois reinos, é sustentada pela menção de alguns deles em textos extra bíblicos. [...] Também a exata duração dos reinados para esses e outros reis parece confiável, na medida em que são diferentes dos 40 anos cada, dados a Davi e Salomão fundadores da dinastia davídica. O último é um número tipológico, significando não mais que 'muito tempo', ou 'muitos anos'. Isso significa que o antigo historiador deuteronomista do final do século VII a.C. tinha acesso a um registro dos reis israelitas e judaítas (FINKELSTEIN, 2015, p. 86-87. Também KNAUF; GUILLAUME, 2016, p. 67)
\end{abstract}

\title{
Davi em Jerusalém: rei de Judá e de "Israel"
}

Após a neutralização da casa de Saul, em 952-951 a.C., possivelmente também com apoio dos filisteus (recompensa por serviços prestados?), Davi entrou em Jerusalém, fazendo desta pequena cidade murada a sua capital (2Sm 5,6-9). Deve-se notar que o corpo de guarda permanente da cidade de Jerusalém é formado por um grupo de filisteus, que nos textos são chamados de feleteus ou peleteus (2Sm 8,18; 20,7; 1Rs 1,38.44).

Instalado em Jerusalém, Davi confiscou a arca de Javé (2Sm 6,1-19). A arca era importante para a mobilização dos camponeses para a luta armada. Era um dos mais importantes símbolos religiosos dos camponeses de Israel norte antigo. Para isso também deve ter contado com o apoio dos filisteus, pois a arca havia sido tomada pelos filisteus (1Sm 4,10-11). Após a colaboração de Davi com os filisteus na guerra contra Saul, os filisteus devolveram a arca de Javé para Israel $(1 \mathrm{Sm} 6,21-7,1)$ através de Obed-Edom, o Gatita, da cidade filisteia de Gat (2Sm 6,11-12). Davi a tomou e a colocou para dentro dos muros de Jerusalém, sob seu controle. Aqui possivelmente começa a nascer a narrativa de Davi como "o homem conforme o coração de Javé".

A ligação de Davi com os filisteus se manterá em todo seu reinado, pois, pouco mais tarde, quando Davi foge de Jerusalém por causa da revolta de Absalão e de setores do Israel norte, ele receberá rapidamente o apoio de um grupo de mercenários filisteus vindos de Gat (2Sm 15,17-22). É certamente como vassalo dos filisteus que Davi poderá estender seu poder sobre terras de 
Benjamim. Certamente irá integrar aos seus domínios todo o, ou pelo menos a maior parte do, centro político administrativo de Saul, o território que acima chamamos de platô Gabaon - Betel, porém possivelmente sem incluir Betel. Isso pode explicar por que várias das cidades dali ficaram despovoadas ou tiveram a população bastante reduzida nesse período (FINKELSTEIN, 2015, p. 60-61).

As narrativas das revoltas de Absalão e de Seba talvez contribuam para a reflexão sobre os limites da área dominada por Davi. A primeira teria sido dentro de sua própria casa, com seu filho Absalão tentando assumir o poder. A redação deuteronomista que encontramos em nossa Bíblia hoje diz que Absalão buscou o apoio dos israelitas (2Sm 15,1-6), como se fosse de todas as tribos de Israel, porém, concretamente são mencionados apenas grupos de

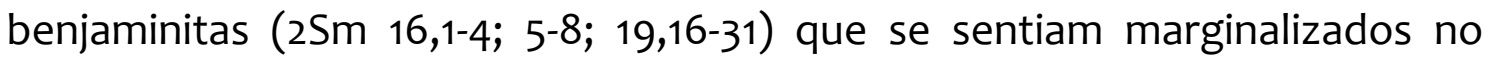
reinado de Davi (2Sm 15,1-6). A segunda revolta (2Sm 20,1-22), avaliada por Davi como mais perigosa do que a revolta de Absalão (2Sm 20,6), é liderada por Seba, explicitamente apontado como sendo membro da tribo de Benjamim $(2 \mathrm{Sm} 20,1)$. A revolta de Seba é mais importante porque, desvinculada do grupo dos donos de bois de Saul (1Sm 10,4-7), parece ter sido uma tentativa de rearticular o exército camponês de Benjamim e talvez com o apoio de Efraim (2Sm 20,21).

O reino de Judá, ao contrário do que afirmam os textos bíblicos, foi muito modesto em quantidade de terras férteis e de homens. Aliás, durante toda a sua existência Judá sempre será bem menos importante na guerra, na política e na economia do que seu vizinho do norte, Israel. Permanecerá quase a maior parte do tempo à sombra do reino do norte (FINKELSTEIN, 2015, p. 15), até a invasão assíria derrotar e desmantelar o reino de Israel em 722 a.C. O "reino de Israel" (2Sm 5,1-3) governado por Davi muito provavelmente estendia-se da Bersabeia, ao sul, até parte do território de Benjamim, ao norte, praticamente a mesma área que era controlada por Saul (DIETRICH, 2020, p. 236-237. A anexação de pelo menos parte do território e da tribo de Benjamim explica a existência da longa narrativa chamada "História da ascensão de Davi ao Trono" (1Sm 16 - 2Sm 6), para dar legitimidade para Davi como sucessor de Saul no governo daquela região. 
Assim sendo, apesar de a Bíblia afirmar que Davi constituiu um império na região (2Sm 8,1-14), ou que seu poder ia de “Dã até a Bersabeia” (2Sm 24,2), historicamente se pode dizer que Davi teve domínio efetivo restrito apenas a uma pequena área de leste a oeste, “do Jordão até Jerusalém” (2Sm 20,2), e de sul a norte indo de Bersabeia até parte do platô Gabaon - Betel, que fora o centro das ações de Saul, na terra de Benjamim (1Rs 12,20-21).

\section{Considerações finais}

Após a morte de Saul, ao redor de 958 a.C., Davi, possivelmente com apoio dos filisteus, forma um pequeno reino em torno de Hebron, na região da montanha de Judá, o reino de Judá; conquista Jerusalém e toma uma parte do antigo centro de operações de Saul, um território Benjaminita até Gaba Gabaon. No entanto, nesta mesma época Abner, o comandante do exército de Saul, e Mefibaal ou Meribaal/Mefiboset, um filho de Saul, por seis ou sete anos tentam rearticular e dar continuidade ao poder de Saul, a partir de Maanaim, e permanecem como um pequeno reino paralelo e em disputa com o reino de Davi. Entretanto, não conseguem manter-se, e a dinastia de Saul termina mais ou menos em 952 ou 951 a.C.

O reinado de Davi, iniciado por volta de 958 a.C., vai até por volta de 940 a.C. Considerando-se que Davi já devia ser um adulto maduro quando entrou em conflito com a casa de Saul e colocou-se a serviço dos filisteus, onde deve ter ficado também vários anos, o seu tempo de reinado pode ter durado em torno de 20 anos. Sua vida pública, contando desde sua entrada no grupo de chefes militares de Saul, deve ter iniciado 5 ou 10 anos antes de entrar em conflito pela sucessão de Saul. Isto, somado aos anos de reinado, totalizaria 30 ou 35 anos. A narrativa bíblica fala em 40 anos (1Rs 2,11). Porém, como já vimos acima, este número dado como a duração do reinado do fundador da dinastia não é exato — significa simplesmente "muitos anos" ou "um longo tempo".

O reino de Judá se manterá com centro em Jerusalém. Porém o grupo que tomou o poder com Davi não conseguirá continuar no poder. Isso é contado na Bíblia em um conjunto de textos que ficou conhecido como a "História da sucessão de Davi", ou a "História da ascensão de Salomão ao poder". Este conjunto de textos está em 2Sm 9-20 e 1Rs 1-2, e pode conter 
informações históricas sobre a violenta disputa desencadeada no momento da sucessão de Davi.

Estes textos mostram que, quando envelhece, Davi perde sua capacidade de comando (1Rs 1,1-4). Sua sucessão será disputada entre os filhos que Davi teve com suas várias mulheres e suas respectivas famílias. É o que normalmente ocorre no período da sucessão. Os filhos do rei ("príncipes" cf. $2 \mathrm{Sm} \mathrm{8,18),} \mathrm{juntamente} \mathrm{com} \mathrm{as} \mathrm{famílias} \mathrm{de} \mathrm{suas} \mathrm{mães,} \mathrm{buscam} \mathrm{juntar} \mathrm{o} \mathrm{maior}$ poder possível, fazendo alianças e articulações econômicas, políticas, militares e religiosas ${ }^{16}$. Quem conseguisse acumular mais poder colocava seu representante no trono $\mathrm{e}$ os grupos derrotados geralmente eram exterminados para evitar intrigas e futuras tentativas de golpe ou rebeliões contra o novo rei. Foi o que fez Davi com os descendentes de Saul, apesar de a narrativa bíblica dizer que Davi jurou não fazer isso (1Sm 24,22-23). O grau de violência que estas disputas podiam alcançar pode ser visto também na luta pela sucessão de Davi.

São as violências que acompanharam Davi em sua história que permitem perceber o Javé que o escolheu e que, através do controle da arca, foi usado para legitimar Davi, apresentando-o como o "homem conforme o coração de Javé". Isto refere-se ao Javé oficial, patrocinador do rei e de suas ações. $O$ sagrado Javé, que seguiu no coração dos camponeses e que se fará ouvir nas bocas dos profetas e se manifestará em Jesus, é outro. Ele não busca, não se apega e nem legitima o poder. É o Javé que está em defesa da vida e da liberdade dos camponeses, e na proteção dos pobres, dos órfãos e das viúvas.

\section{Referências}

\footnotetext{
${ }^{16}$ Embora o sistema patriarcal de Israel não desse espaço para as filhas do rei, as mulheres do rei tinham papéis muito importantes tanto na educação e preparação do filho para assumir 0 trono como também nas articulações políticas para fazer que ele chegasse a ser o rei. Nesse caso elas continuavam a ter um papel importante como conselheiras do rei. A indicação do nome da mãe do rei juntamente com o nome do rei ( 1 Rs 14,21; 15,2 etc.) indica que ela era uma espécie de co-regente, ou conselheira principal. Ela recebia o título de Geviráh, que significa "mulher forte", era a "rainha mãe". Essa influência podia estender-se não somente sobre seu filho no poder, mas também ao neto que o sucedesse, como no caso de Maaca (1Rs 15,2.10). As mulheres também podiam ter influência semelhante no campo militar, pois não somente Joab, o comandante, como também Abisaí e Asael, dois importantes chefes guerreiros, do exército de Davi, são quase sempre nomeados com referência a sua mãe: "filhos de Sarvia" (1Sm 26,6; 2Sm $2,18 ; 3,39 ; 14,1 ; 16,9)$.
} 
ANDERSON, J. S. Monotheism and Yahweh's Appropriation of Baal. London/New York: Bloomsbury T \& T Clark, 2015.

ATHAS, G. The Tel Dan Inscription: A Reappraisal and a New Introduction. London/New York: T\&T Clark International, 2003.

BADEN, J. Davi: a vida real de um herói bíblico. Rio de Janeiro: Zahar, 2016.

BODNER, K.; JOHNSON, B. J. M. David: Kaleidoscope of a King. In: BODNER, K.; JOHNSON, B. J. M. Characters and Characterization in the Book of Samuel. Oxford: T\&T Clark, 2019. p. 121-138. (The Library of Hebrew Bible/Old Testament Studies, 669).

BOSWORTH, D. A. Evaluating King David: Old problems and recent scholarship. The Catholic Biblical Quarterly. Washington, DC, v. 68, n. 2, p. 191-210, Apr. 2006.

CARR, D. M. The formation of the Hebrew Bible. A New reconstruction. New York: Oxford University Press, 2011.

DAVIES, P. R. "House of David" Built on Sand: The Sins of the Biblical Maximizers. Biblical Archaeology Review. Washington, v. 20, n. 4, Jul./Aug. 1994.

DAY, J. Yahweh and the gods and goddesses of Canaan. London/New York: Sheffield Academic Press, 2000.

DIETRICH, L. J. Quem matou Saul? Revista Estudos de Religião, São Paulo, v. 34, n. 1, p. 225-254, jan./abr. 2020.

DIETRICH, L. J. O processo e a função social da produção da imagem de Davi como pastor que fala em nome de Yhwh zebaot, em 1 Samuel 17.1-18,5. 2002. 281 p. Tese (Doutorado em Literatura e religião no mundo bíblico) — Universidade Metodista de São Paulo, São Bernardo do Campo, 2002.

DIETRICH, W. The early monarchy in Israel. The tenth century B.C.E. Atlanta: Society of Biblical Literature, 2007. (Biblical Encyclopedia/Biblische Enziclopädie, v. 3).

FAUST, A. A Social Archaeology of the Kingdom of Judah: From Prehistory to the Present. In: YASUR-LANDAU, A.; CLINE, E. H.; ROWAN, Y. M. The Social Archaeology of the Levant. Cambridge/New York: Cambridge University Press, 2019. p. 337-353.

FAUST, A. From regional power to peaceful neighbor. Philistia in the Iron I-II transition. Israel Exploration Journal, v. 63, p. 154-173. 2013.

FAUST, A. Proof of King David? Not yet. But riveting site shores up roots of Israelite era. The Times of Israel. 14 May 2018. Disponível em: https://www.timesofisrael.com/proof-of-king-davidnot-yet-but-riveting-site-shoresup-roots-of-israelite-era/ Acesso em: 20 jan. 2020.

FAUST, A. The Large Stone Structure in the City of David. A Reexamination. Zeitschrift des Deutschen Palästina-Vereins. Wiesbaden, v. 126, p. 116-130, 2010. 
FINKELSTEIN, I. Is the Philistine paradigm still viable? In: BIETAK, M.; CZERNY, E. (Eds.). The synchronization of civilisations in the Eastern Mediterranean in the Second Millennium B.C. Vienna: Austrian Academy of Sciences Press, 2007. p. 517-523.

FINKELSTEIN, I. Saul, Benjamim e o surgimento do "Israel Bíblico": uma visão alternativa. Revista Caminhando, São Paulo, v. 20, n. 2, p. 23-43, jul./dez. 2015.

FINKELSTEIN, I. The "Large Stone Structure" in Jerusalem. Reality versus Yearning. Zeitschrift des Deutschen Palästina-vereins, Wiesbaden, v. 127, n. 1, p. 1-10, 2011.

FINKELSTEIN, I.; FANTALKIN, A.; PIASETZKY, E. Three Snapshots of the Iron IIA. The Northern Valleys, the Southern Steppe and Jerusalem. In: GRABBE, L. L. (ed.). Israel in Transition. From Late Bronze II to Iron IIA (c. 1250-850 BCE), I. The Archaeology. New York/London: T\&T Clark, 2008. p. 32-44. (European Seminar in Historical Methodology 7; Library of Hebrew Bible. Old Testament Studies 491).

FINKELSTEIN, l. et al. Has the Palace of King David in Jerusalem been found? Tel Aviv Journal, Tel Aviv, v. 34, p. 142-164, 2007.

FINKELSTEIN, I.; PIAZETSKY, E. The Iron Age chronology debate: is the gap narrowing? Near Eastern Archaeology, Chicago, v. 74, p. 50-54, 2011.

FINKELSTEIN, I.; SILBERMAN, N. A. A Bíblia não tinha razão. São Paulo: A Girafa, 2003. ${ }^{17}$

GALLAZZI, S. Israel na história. Seu povo, sua fé, seu livro. São Leopoldo: CEBI, 2011.

GRABBE, L. Ancient Israel: what do we know and how do we know it? New York: T\&T Clark, 2007.

HALPERN, B. David's secret demons. Messiah, murderer, traitor, king. Cambridge: B. Eerdmans Publishing, 2001.

HALPERN, B. The United monarchy. In: EBELING, J. et al. (Eds.). The Old Testament in archaeology and history. Waco, Texas: Baylor University Press, 2017. p. 337-362.

KAEFER, J. A. "A Estela de Dã". Caminhando, v. 17, n. 2, p. 33-46, jul./dez. 2012.

KAEFER, J. A. A Bíblia, a arqueologia e a história de Israel e de Judá. São Paulo: Paulus, 2015.

KNAUF, E. A.; GUILLAUME, P. A History of Biblical Israel. The fate of the kingdoms from Merenptah to Bar Kochba. Sheffield, U.K./Bristol: Equinox, 2016.

\footnotetext{
${ }^{17}$ Este livro conta com uma tradução melhor e com um título de acordo com o título da obra original: $A$ Bíblia desenterrada. Nova visão arqueológica do antigo Israel e das origens de seus textos sagrados. Petrópolis: Vozes, 2018.
} 
$\mathrm{KOCH}$, I. Early Philistia revisited and revised. In: LIPSCHITS, O.; GADOT, Y.; ADAMS, M. (Eds.). Rethinking Israel. Studies in the history and archaeology of ancient Israel in honor of Israel Finkelstein. Winona Lake, Indiana: Eisenbrauns, 2017. p. 189-205.

LEUCHTER, M. A.; LAMB, D. T. The historical writings. Introducing Israel's historical literature. Minneapolis: Fortress Press, 2016.

LIPINSKI, E. A History of the Kingdom of Israel. Leuven/Paris/Bristol: Peeters, 2018. (Orientalia Lovaniensia Analecta, 275).

LIVERANI, M. Para além da Bíblia. História antiga de Israel. São Paulo: Paulus/Loyola, 2008.

MAEIR, A. M.; HITCHKOCK, L. A. Rethinking the philistines. In: LIPSCHITS, O.; GADOT, Y.; ADAMS, M. (Eds.). Rethinking Israel. Studies in the history and archaeology of ancient Israel in honor of Israel Finkelstein. Winona Lake, IN: Eisenbrauns, 2017. p. 247-266.

MAZAR, A. Archaeology and the Biblical Narrative. The Case of the United Monarchy. In: KRATZ, R. G.; SPIECKERMANN, H. (eds.). One God - One Cult - One Nation. Archaeological and Biblical Perspectives. Berlin/New York: De Gruyter, 2010. p. 29-58. (Beihefte zur Zeitschrift für die Alttestamentliche Wissenschaft 405).

MAZAR, E. Did I Find King David's Palace? Biblical Archaeology Review, Washington, v. 32, n. 1, p. 16-27, jan./fev. 2006.

MAZAR, E. Preliminary Report on the City of David. Excavations 2005 at the Visitors Center Area. Jerusalem: Shalem Press, 2007. ${ }^{18}$

MAZAR, E. The Palace of King David. Excavations at the Summit of the City of David. Preliminary Report of Seasons 2005-2007. Jerusalem/New York: Shoham Academic Research and Publication, 2009. ${ }^{19}$

McCARTER, P. K. The apology of David. Journal of Biblical Literature, Atlanta, v. 99, p. 489-504, 1980.

MCKENZIE, S. L. King David: A Biography. New York: Oxford University Press, 2000.

MILLER, J. M.; HAYES, J. H. A history of ancient Israel and Judah. Louisville/London: Westminster John Knox Press, 2006.

RAINEY, A. F., The 'House of David' and the House of the Deconstructionists. Washington, Biblical Archaeology Review, v. 20, n. 6, p. 47, nov./dez. 1994.

\footnotetext{
${ }^{18}$ Citado por: FINKELSTEIN, I. The "Large Stone Structure" in Jerusalem. Reality versus Yearning. Zeitschrift des Deutschen Palästina-vereins, Wiesbaden, v. 127, p. 1-10, 2011.

${ }^{19}$ Citado e contestado por: FINKELSTEIN, I. The "Large Stone Structure" in Jerusalem. Reality versus Yearning. Zeitschrift des Deutschen Palästina-vereins, Wiesbaden, v. 127, p. 1-10, 2011.
} 
REIMER, H. Inefável e sem forma. Estudos sobre o monoteísmo hebraico. São Leopoldo/Goiânia: Oikos/UCG, 2009.

REIMER, H. O antigo Israel. História, textos e representações. São Paulo: Fonte Editorial/Editora UEG, 2017.

SCHNIEDEWIND, W. M. Como a Bíblia tornou-se um livro. A textualização no Antigo Israel. São Paulo: Loyola, 2011.

SCHWANTES, M. Breve história de Israel. 2. ed. São Leopoldo: OIKOS, 2008.

SKA, J-L. O canteiro do Pentateuco. Problemas de composição e de interpretação: aspectos literários e teológicos. São Paulo: Paulinas, 2016.

SMITH, M. S. The early history of God: Yahweh and the other deities in Ancient Israel. San Francisco: Harper \& Row, 1990.

ZABATIERO, J. P. T. Uma história cultural de Israel. São Paulo: Paulus, 2013. 